William Gault's detailed "Observations on the Geology of the Black Mountains," a coloured diagram is given. The Appendix contains papers by Mr. Joseph Wright on "Recent Foraminifera of Down and Antrim," and by Messrs. Swanston and Lapworth on the "Correlation of the Silurian Rocks of Co. Down."

THE Twentieth Report of the East Kent Natural History Scciety is, on the whole, satisfactory. It contains abstracts of several good papers read at the meetings. The Society has ninety.three members.

Excavations in the "Dragon Cave" at Mixniz, Styria, have been already noticed (NATURE, vol. xviii. p. 6r8). The diggings made in June, 1878 , by the Anthropological Society of Gratz, have brought to light some bones bearing indistinct marks of cutting and percussion. Above the stalagmitic layer over the hearth-stuff some bones were found, in loam, well preserved, but probably derived from an older site. They are greenish, and partly of an intense bluish-green tint; and Prof. C. Doelter finds that their composition approaches that of turquoise [boneturquoise?]. A full account by Prof. R. Hoernes will be found in the Proc. Imp. Geol. Instit. Vienna, August 31, 1878.

THE additions to the Zoological Society's Gardens during the past week include a Yellow Baboon (Cynocephalus babouin), from West Africa; two Ring-tailed Lemurs (Lemur catta), from Madagascar, presented by Mr. G. A. Shaw; a Green Monkey (Cercopithecus callitrichus), from West Africa, presented by Mr. J. Williams; a Common Fox (Canis vulpes), British, presented by Mr. Sutton Sharpe; a Woodcock (Scolopax rusticola), European, presented by Messrs. E. and W. H. Davis; a Common Swan (Cygrzus olor), European, presented by Capt. Marx; a Ring-tailed Lemur (Lemur cattri), from Madagascar, deposited; an Ocelot (Felis pardalis), from America; a Cereopsis Goose (Cereopsis nova-hollandia), from Australia; three Yellow-winged Blue Creepers (Coreba cyanea), from South America, purchased.

\section{ON HELIOTROPISM IN PLANTS}

THE heliotropic phenomena in plants form the subject of a monograph by Herr Wiesner, the first part of which has been recently communicated to the Vienna Academy. The following outline from the Anzeiger of the Academy will give an idea of some of the fruits of the author's researches on this important subject.

The first section treats of the history of the subject. In the second section the author studies the influence of light on heliotropism. The experiments were made in the light of a gas flame which burned under a constant pressure with a uniform intensity (luminous power $=6 \cdot 5$ spermaceti candles). The unit for the measurement of the light-intensity was the strength of this flame at the distance of one metre. It was found that in heliotropism three cardinal points of lightintensity are to be distinguished; an upper limit, a lower limit, and between the two an optimum of light intensity. Thus with decreasing intensity of light the strength of the heliotropic effect increases to a certain point, and beyond this point decreases. The lower limit referred to coincides with the lower limit of light-intensity for the stoppage of growth in length, while the upper limit does not coincide, or only occasionally coincides, with the upper limit of light-intensity for growth in length, for in the case of plants very sensitive heliotropically it lies higher, and in less sensitive plants lower, than the upper limit for growth in length. The mode of arrangement of the experiment in gas-light did not permit of determining in all cases the limiting values of the light-intensities; thus, for example, the upper limit for the heliotropism of etiolated shoots of Salix alba, and of the hypocotylous portion of the stem of Viscum album, and the lower limit for the heliotropism of the growing stem of vetch could not be ascertained. The former lies above 400 , the latter far below 0.008. The optima were found to lie bctween 0:II (the growing stem of the pea) and 6.25 (etiolated shoots. of Salix alba). Both with gas.light and with natural light it was ascer- tained that beyond a certain intensity no growth in length occurs.

The third section treats of the relations between the refrangibilizy of the light rays, and the heliotropic effects. The experiments were made partly in the objective spectrum, partly in varieties of light, got by sending white light throngh coloured solutions. . . . It was proved that portions of plants very sensitive heliotropically, e.g., growing stems of Vicia sativa, undergo curvatures in all kinds of light, even in ultra-red and ultra-violet, with the exception of yellow. The maximum of the heliotropic force of light lies at the boundary between violet and ultra-violet ; a second (smaller) in the ultra-red. From both maxima the power of the rays to produce heliotropism decreases gradually on to the yellow. Portions of plants little sensitive heliotropically, are no longer influenced by orange, or by red and green, or even (in the case of etiolated shoots of Salix alba) by ultra-red rays. The yellow rays quite stop the heliotropism, for, e.g., in pure red a quicker and stronger heliotropism occurs than in a light which gives yellow besides red.

In the fourth section experiments are described on the joint action of (positive and negative) heliotropism and (positive and negative) geotropism. It is here shown, inter alia, that, in the case of plauts very sensitive heliotropically, the geotropism is, at the optimum of light-intensity, apparently extinguished, even in strongly geotropic organs; further, that in many organs (growing stem of the pea), the heliotropic and geotropic powers of curvature disappear simultaneously; in others, however (stems of cress), the younger portions of the stem are more strongly heliotropic than the older, and the oldest after-growing portions of stem no longer show bendings in the light, but, through drawing action on one side (the heliotropic overhanging point of the stem), show apparently heliotropic curvatures/ chiefly due to growth, which are then counteracted by negative geotropism.

The arguments which go to prove that heliotropism is due to the phenomenon of unequal growth upon unequally-lit sides of an organ are set forth in the next section, and proof is offered that, for heliotropism as well as for growth in length, free oxygen is necessary.

The last chapter furnishes proof that the conditions for heliotropism remain constantly the same during its course, and coincide with the conditions for growth in length; further, that heliotropism (and the same holds good for geotropism) occurs as a phenomenon of induction. In this chapter it is also shown that when light induces heliotropism in an organ; a frèsh heliotropic or geotropic induction meets with resistances, and can only come into action after extinction of action of the first; and that successive impulses of light and gravity, of which each by itself is capable of producing certain effects, do not have their actions added together when the effects that should be obtained separately are in the same direction, e.g., one and the same side of the organ is helped in its growth in length.

\section{SOCIETIES AND ACADEMIES} LONDON

Royal Society, December 5.- "On a Machine for the Solution of Simultaneous Linear Equations," by Sir William Thomson. Let $B_{1}, B_{2}, \ldots \mathrm{B}_{t}$ be $n$ bodies each supported on a fixed axis (in practice each is to be supported on knife-edges like the beam of a balance).

Let $P_{11}, P_{21}, P_{31}, \ldots P_{n}$ be $n$ pulleys, eacls pivoted on $B_{1}$;

i $\begin{array}{llll}P_{12}, P_{22}, P_{32}, \ldots P_{n 2} & , & , & B_{2} \\ P_{13}, P_{33}, \ldots P_{n 3} & \text { ", } & \text { ", } & B_{3} ;\end{array}$

", $C_{1}, C_{2}, C_{3} \ldots C_{n}$, be $n$ cords passing over the pulleys ;

", $D_{1}, P_{11}, P_{12}, P_{13}, \ldots P_{1 n}, E_{1}$, be the course of $C_{1}$;

"D $D_{2}, P_{21}, P_{22}^{12}, P_{23}^{13}, \ldots P_{2^{n}}, E_{2},,, \quad, \quad C_{2}$;

$, D_{1}, E_{1}, D_{2}, E_{2} \ldots D_{n}, E_{n}$, be fixed points ; " $l_{1}, l, l_{3}, \ldots l_{n}$ be the lengths of the cords between $D_{1}, E_{1}$,
and $D_{2}, \mathrm{E}_{2}, \ldots$ and $D_{n}$, and $\mathrm{E}_{n}$, along the courses stated above, when $B_{1}, B_{2}, \ldots B_{n}$, are in particular positions which will be called their zero positions;

Let $l_{1}+e_{1}, \ldots l_{2}+e_{2}, \ldots l_{n}+e_{n}$ be their lengths between the same fixed points, when $B_{1}, B_{2}, \ldots B_{n}$ are turned through angles $x_{1}, x_{2}, \ldots x_{n}$ from their zero positions;

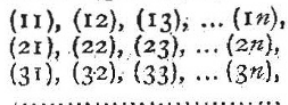


quantities such that

$$
\begin{aligned}
& \text { (I I) } x_{1}+\text { (I2) } x_{2}+\ldots+\text { (I } n \text { ) } x_{n}=e_{3} \\
& \text { (31) } x_{1}+\left(3^{2}\right) x_{2}+\ldots+\left(3^{n)} x_{n}=e_{3}\right. \\
& (n \mathrm{1}) x_{1}+(n 2) x_{2}+\ldots+(n n) x_{n}=e_{n}
\end{aligned}
$$

We shall suppose $x_{1}, x_{2}, \ldots x_{n}$ to be each so small that (II), (12), ... (2I), \&c., do not vary sensibly from the values which they have where $x_{1}, x_{2}, \ldots x_{n}$, are each infinitely small. In practice it will be convenient to so place the axes of $B_{1}, B_{2}, \ldots B_{n}$, and the mountings of the pulleys on $B_{1}, B_{2}, \ldots B_{n}$, and the fixed points $D_{1}, E_{1}, D_{2}$, \&c., that when $x_{1}, x_{2}, \ldots x_{n}$ are infinitely small, the straight parts of each cord and the lines of infinitesimal motion of the centres of the pulleys round which it passes are all parallel. Then $\frac{1}{2}(\mathrm{II}), \frac{1}{2}(2 \mathrm{I}), \ldots \frac{2}{2}(n \mathrm{I})$ will be simply equal to the distances of the centres of the pulleys $P_{11}, P_{21}, \ldots P_{n 1}$, from the axis of $B_{1}$;

$\frac{1}{2}(12), \frac{1}{2}(22) \ldots \frac{1}{2}(n 2)$ the distances of $P_{12}, P_{22}, \ldots P_{n 2}$ from the axis of $B$, and so on.

In practice the mountings of the pulleys are to be adjustable by proper geometrical slides, to allow any prescribed positive or negative value to be given to each of the quantities (II), (12), ... (2I), \& c.

Suppose this to be done, and each of the bodies $B_{1}, \mathrm{~B}_{2}, \ldots \mathrm{B}_{n}$ to be placed in its zero position and held there. Attach now the cords firmly to the fixed points $D_{1}, D_{2}, \ldots D_{n}$ respectively; and, passing them roand their proper pulleys, bring them to the other fixed points $E_{1}, E_{2}, \ldots E_{n}$, and pass them through infinitely small smooth rings fixed at these points. Now hold the bodies $B_{1}, B_{2}, \ldots$ each fixed, and (in practice by weights hung on their ends, outside $E_{1}, E_{2}, \ldots E_{n}$ ) pull the cords through $E_{1}, E_{2}, \ldots E_{n}$ with any given tensions ${ }^{1} T_{1}, T_{2}, T_{n}$. Let $G_{1}, G_{2}, \ldots G_{n}$ be moments round the fixed axes of $B_{1}, B_{2}, \ldots B_{n}$ of the forces re. quired to hold the bodies fixed when acted on by the cords thus stretched. The principle of "virtual velocities," just as it eame from Lagrange (or the principle of "work"), gives immediately, in virtue of (I),

$$
\left.\begin{array}{l}
G_{1}=(\mathrm{II}) T_{1}+(2 \mathrm{I}) T_{2}+\ldots+(n \mathrm{I}) T_{n} \\
G_{2}=(\mathrm{I} 2) T_{1}+(22) T_{2}+\ldots+(n 2) T_{n} \\
\ldots \ldots \ldots \ldots \ldots \ldots \ldots \ldots \ldots \ldots \ldots \ldots \ldots \ldots \ldots \ldots \ldots \ldots \ldots \ldots \ldots \ldots \ldots \ldots \ldots \ldots \\
G_{n}=(\mathrm{I} n) T_{1}+(2 n) T_{2}+\ldots+(n n) T_{n}
\end{array}\right\}
$$

Apply and keep applied to each of the bodies, $B_{1}, B_{2}, \ldots B_{n}$ (in practice by the weights of the pulleys, and by counter-pulling springs), such forces as shall have for their moments the values $G_{1}, G_{2}, \ldots G_{n}$, calculated from equations (II) with whatever values seem desirable for the tensions $T_{1}, T_{2}, \ldots T_{n}$. (In practice, the straight parts of the cords are to be approximately vertical, and the bodies $B_{1}, B_{2}, \ldots, B_{n}$ are to be each balanced on its axis when the pulleys belonging to it are removed, and it is advisable to make the tensions each equal to half the weight of one of the pulleys with its adjustable frame.) The machine is now ready for use. To use it, pull the cords simultaneously or successively till lengths equal to $e_{1}, e_{2}, \ldots e_{i 2}$ are passed through the rings $E_{1}$, $E_{0}, \ldots E_{n}$, respectively,

The pulls required to do this may be positive or negative; in practice, they will be infinitesimal, downward or upward pressures applied by hand to the stretching weights which remain permanently hanging on the cords.

Observe the angles through which the bodies $B_{1}, B_{2}, \ldots B_{n}$ are turned by this given movement of the cords. These angles are the required values of the unknown $x_{1}, x_{2}, \ldots x_{n}$, satisfying the simultaneous equations (I).

The actual construction of a practically useful machine for calculating as many as eight or ten or more of unknowns from the same number of linear equations does not promise to be either difficult or over-elaborate. A fair approximation being found by a first application of the machine, a very moderate amount of straightforward arithmetical work (aided very advantageously by Crelle's multiplication tables) suffices to calculate the residual errors, and allow the machines (with the setting of the pulleys unchanged) to be re-applied to calculate the corrections (which may be treated decimally, for convenience) : thus, 100 times the amount of the correction on each of the

? The idea of force here first introduced is not essential, indeed is not tech nically admissible to the purely kinematic and algebraic part of the subject proposed. But it is not merely an ideal kinematic construction of the algepraic problem that is intended; and the design of a kinematic machine, for succes in practice, essentially involves dynamical considerations. In the present case some of the most important of the purely algebraic question

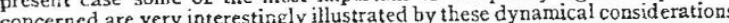

original unknowns, to be made the new unknowns, if the magnitudes thus falling to be dealt with are convenient for the machine. There is, of course, no limit to the accuracy thus obtainable by successive approximations. The exceeding easiness of each application of the machine promises well for its real usefulness, whether for cases in which a single application suffices, or for others in which the requisite accuracy is reached after two, three, or more of successive approximations.

Mathematical Society, December I2.-Mr. C. W. Merrifield, F.R.S., president, in the chair.-Prof. W. S. Jevons, F.R.S., was elected a Member.-The following communications were made to the Society:--Mr. H. Perigol, on a kinematic paradox (the rotameter); Mr. S. Roberts, F.R.S., on the forms of numbers determined by continued fractions ; Prince Camille de Polignac, on a graphic construction of the powers of a linear substitution.

Linnean Society, December 5.-Prof. Allman, F.R.S. president, in the chair-Dr. I. Bayley Balfour demonstrated the peculiarities of a rare Myxomycetes, which species of Heterodictyum he showed bore characters intermediate between Cribraria and Dictydium.-Mr. G. Murray called attention to a peculiar greenish-yellow fungus (Hygrophornes Wynnice, Berk. ?) from Bridlington, Yorkshire.-Examples of a moss new to Britain, the Aulacomnion turgidum, were shown by Mr. E. M. Holmes, who stated that they were found by $\mathrm{Mr}$. West and $\mathrm{Dr}$. F. Arnold Lees in Yorkshire; a comparison between the above and the common $A$. palustre was made.-Mr. F. H. Waterhouse read a paper on some Coleoptera collected by Charles Darwin, of geographical interest. These had lain undetermined for a long series of years, and now prove new to science. Phytosus Darwinii, from the Falklands, has unusually long. slender claws; Choleva falklandica is elliptical-shaped and strongly punctated. Elmis brunnea and Antricus Wollastoni, from St. Helena, are noteworthy, inasmuch as $\mathrm{Mr}$. Wollaston ("Coleop. St. Hel.") does not record either genus as existent there. Scaphisoma elongatum, from Rio de Janeiro, is the first species of the genus known to inhabit South America and Prosthetops ( $P$. capcnsis) is a novel genus with two ocelli, from Sonth Africa.-Mr. C. B. Clarke, in a note on Gardenia turgida, stated that in books the flower calyx of males was alone described, while all herbaria specimens are diocious, and males and females have hitherto been referred to different genera. The precise characters of each were denoted.-Dr. F. Day gave a summary of his (third) concluding paper on the geographical distribution of the Indian fresh-water fishes, in this dealing with the families Scombresocidæ, Cypriodontidæ, Cyprinidæe, Notopteridx, and Symbranchidx. Among the eighty-seven genera two only are African, thirty-two extend to the Malay Archipelago, and twelve are common to Africa and Malaya ; of 369 species two are African, twenty-seven Malayan, and two common to both regions. In short, the fresh-water fish affinities preponderate to the Indo-Chinese and Malayan sub-regions; thus supporting Mr. Wallace's opinion as opposed to the view held by Mr. Blandford, who gives greater weight to African relationships, at least so far as mammals are concerned. Dr. Day, moreover, contends that the Indian fresh-water fishes point to three subordinate separate faunas--I. That belonging to the Ghauts, Ceylon, the Himalayas, and Malay Archipelago; wherein may be distinguished two fish races, a Palrearctic and a Malayan. 2. A fauna of the plains west of the Indus, with an African element in it. 3. That (by far the largest) spread over the plains east of the Indus, and which appears to have a Burmese connection. - The abstract was read of a second contribution on the mollusca of the Challenger Expedition, by the Rev. R. Boog Watson. This consisted of descriptions of species of Trochidæ belonging to four genera, viz., Sequinzia, Basilissa, Gazd, and Bembix; the three last being new and otherwise remarkable.-Messrs. Dowdeswell, Arthur Hammond, Thos. Hanbury, Joseph Sidebotham, Wm. Thomson, and Chas. A. Wright were elected Fellows of the Society.

Zoological Society, December 3.-Mr. Robert Hudson, F.R.S., vice-president, in the chair.-Mr. H. Seebohm, F.Z.S., exhibited a series of specimens of the hooded and carrion crows, and made remarks on their intermediate forms and geographical distribution.-Col. L. H. Loyd Irby, F.Z.S., exhibited and made remarks on the nests, eggs, and young of Cypselus pallidus, taken at Gibraltar.-Mr. Howard Saunders, F.Z.S. exhibited and made remarks on some eggs of Indian Laridx (Sterna bergii and Larus hemprichii), which had been taken by 
Capt. Butler, of H.M.'s 83 rd Regt., on the Mekran Coast.-Dr. Day, F.Z.S., exhibited and made some remarks on some jaws of Indian sharks belonging to the genera Galeocerdo and Carcarias. - The Secretary called attention to an error which had been made in reference to the collection of butterflies from Billiton, reported on by Messrs. Godman, Salvin, and Druce, in the last part of the Society's Proceedings. The collection had been made and forwarded to England by Herr J. G. F. Riedel, of Koepang. -Mr. Sclater communicated some further particulars respecting the occurrence in Lancashire of the specimen of the blackthroated Wheatear (Saxicola stapazina) exhibited at the last meeting of the Society.--Prof. A. H. Garrod, F.R.S., read a paper on the conformation of the thoracic extremity of the trachea in the birds of the order Gallinx.-A communication was read from Dr. A. Gïnther, F.R.S., containing the description of some reptiles from Midian, collected by Major Burton. Amongst these were two new snakes proposed to be called Echis decorata and Zanturis elegantissima.-Mr. H. Seebohm pointed out the character of a new Sylvia from Abyssinia, proposed to be called Sylvia blanfordi, after Mr. Blanford, by whom it was obtained during the Abyssinian Expedition.-Mr. H. Seebohm also read notes on the identity of the birds which had been named Hororni fortipes, Neornis assimilis, Horeites robustipes, H. brunneus and $H$. pallidus, and proposed to reduce them to one species under the name Cettia fortipes. - Mr. Martin Jacoby read descriptions of some new species of Phytophagous Coleop. tera from Central and South Arerica.

Anthropological Institute, November 26.-Mr. John'Evans, F.R.S., president, in the chair.-The Rev. John Robbins, D.D., was announced as a. Member.-Mr. Worthington G. Smith exhibited a series of flint implements from the valley of the River Lea.-Mr. A. L. Lewis read a paper on the evils arising from the use of historical national names as scientific terms. The propositions which he endeavoured to establish were: $\mathrm{I}$. That there were at the first population of Europe certain primi tive races, of which three are particularly described. 2. That these races are so mixed that at the present day the representatives of them appear not only in most European nations, but in the same families and among children of the same parents. 3 . That notwithstanding this mixture and the effects which it must permanently have, racial characters display an astonishing permanence. 4. That this mixture, being so slow in its effects and yet having become so general, has probably been at work for a very great length of time-so great that the peoples to whom the earliest bistory introduces us were probably nearly as much mixed as those of the present day. 5. That it is desirable to discontinue the use of political names of those peoples as ethnic names, and to employ others, based on the physical characteristics of the individual. 6. That while physical characteristics are the only basis for a true division into races, yet in the practical application of this division the influence upon (individuals of different races of a community of language, custoin, history, or tradition must not be lost sight of, although these things do not prove community of race, but only the contact at some time or other of the races to whom they are now common.--The director read a paper by Prof. Daniel Wilson, LL.D., on some American illustrations of the evolution of new varieties of men. In the mingling of different races in America, so complex and varied all subjected to the influences of climate and social habits, and all mingling in blood in a greater or less degree with the native red races, hybridity had resulted on a great scale. The process had already been developed sufficiently long to afford important indications of the evolutions of permanent hybrid varieties. A specimen is to be seen among the tribes of the half-breeds in Manitoba, as it were in the process of evolution; while sheltered within the remote Arctic regions man can be studied among the Esquimaux in conditions closely analogous to those which are ascribed to a post-pliocene, if not to a pre-glacial period. In the abrupt collision of the civilised races of Europe with the American aborigines, it hat always been taken for granted that the latter were doomed to inevitable ex. tinction, and that the land would be peopled with the purely civilised races of the world. There is no question, however, that from an early date there have been intermarriages between Europeans and the American races. A growing feeling is manifesting itself in the United States and Canada that the Indian population is not doomed to extinction, and that a much larger amount of healthy intermarrying and consequent absorption has existed than unobserving critics had any conception of, and the native Indian element is a factor in the population of the New
World destined to exercise an enduring influence on the ethnical character of the Euro-American races.

\section{CAMbridge}

Philosophical Society, November 4.-The following com munications were made to the Society:-The physical constants of hydrogenium, by Prof. Dewar, Part 2. This paper is a continuation of an investigation into the physical constants of hydrogenium. The first part appeared in the Transactions of the Royal Society of Edinburgh, vol. xxvii., and had reference to the specific gravity, specific heat, and coefficient of expansion of the occluded hydrogen. These observations led to the conclusion that the specific gravity was independent of the amount of condensed gas, and had a mean value of 0.62 . This result has been confirmed by the subsequent experiments of Troost and Hautefeuille, and what is very remarkable, they deduce an identical value for the density of hydrogen from observations on the hydrides of potassium and sodium. The specific heat, relatively to palladium, of the condensed hydrogen, appeared to vary inversely as the charge, but taken relatively to successive charges was nearly constant, and had the value $3 \%$, which is identical with that of gaseous hydrogen at constant pressure. The coefficient of the cubical expansion of the alloy is about twice that of palladium, and that of the hydrogen in its compressed state not more than three times that of mercury. This communication deals with the thermo-electric relations and conductivity of hydrogenium. It is shown that the electro-motive force of a junction of hydrogenium palladium is at ordinary temperatures nearly equal to that of an iron copper junction, and that it increases with the temperature according to the general parabolic law, the rate of the increase being, however, greater than iron copper and subject to a regular variation on account of successive heatings. The formation of thermo-electric piles, and of neutral points in a uniform wire of this substance, along with the continuous formation of thermo-electric currents through the application of a hydrogen flame were explained and shown. Experiments on the electric resistance show that it increases directly as the amount"of condensed gas.-Studies in spectrum analysis, by Professors Liveing and Dewar. The author describe the reversal of characteristic lines of rubidium and crsium when the chlorides are heated with sodium in glass tubes in an atmosphere of hydrogen or nitrogen, and a bright light is viewed through the vapours. They remark that the violet lines of rubidium, and the most refrangible of the cæsium; lines are first seen, and broaden out the most when the temperature rises, contrary to what might have been expected from the analogv of other cases. The absorption lines observed coincided with the bright lines of the metals heated in a flame, not with the lines which they give in a dense electric spark; but the anthors obtained spectra similar to the flame spectra by passing sparks from an induction coil without a Leyden jar, between beads of fused chlorides of those metals, although simpler spectra were produced by the more abrupt discharges produced by interposing a Leyden jar. The authors further described absorption spectra produced by magnesium vapour when mixed with hydrogen, potassium, and sodium respectively. That produced by magnesium and hydrogen consisted of a line a little less refrangible than the $b$ group, and a band rather more refrangible than the $b$ group, fading away towards the blue. The constant appearance of these absorp. tions when the vapour of magnesium in hydrogen was observed in a hot iron tube, led to the endeavour to obtain the corresponding luminous spectrum. This they succeeded in doing by taking sparks from an induction coil, without a Leyden jar between magnesium wires in a tube full of hydrogen. It ap. pears that the compound to which this spectrum is due is formed only within a certain range of temperature, and is dissociated at higher temperatures-for the spectrum is scarcely seen at all when a large Leyden jar is used, which may te supposed to have the effect of shortening the time of discharge and increasing the temperature. Further, this compound does not seem to be formed when the pressure of the hydrogen is much reduced. In the case of sodium and magnesium they observed an absorption line in the green not observed in either vapour separately; and when potassium and magnesium were used, a characteristic pair of lines in the red always appeared, and sometimes another line in the h!ne. The authors have not yet seen these as bright lines. In the course of observations on the spectra of sundry rarefied gases the authors have been led to conclude that electric sparks take a selective course in a mixture of gases, and that the differences in the spectra 
observed in different parts of the same tube are probably due to the existence of more than one gas in the tube. Tubes of nitrogen which did not show the lines of hydrogen at all when sparks from an induction coil without a Leyden jar were passed throngh them, gave strong hydrogen lines when a large jar was interposed. A bulb tube with magnesitum wires filled with hydrogen at low pressure gave in one half scarcely any spectrum but the F-line of hydrogen, while the other half gave the spectrum of acetylene. They generally found hydrogen lines and flashes of sodium (no doubt from the glass) in tubes very much exhausted; and they conclude that impurities enter such tubes from sources hitherto unsuspected. Tubes filled with oxygen obtained from silver iodate have been found to give the spectrum of iodine, pointing to the conclusion that chemical reactions occur at very low pressures which are not produced under other circumstances. Generally the authors conclude that the spectrum of a gas in a rarefied state affords the most clelicate test of its purity, and that it is to the chemical problem of obtaining pure gases that attention needs to be specially directed.

\section{PARIS}

Academy of Sciences, Deceraber 9.-M. Fizeau in the chair.-The following papers were read :-New method for determining the flexion of telescopes, by M. Loewy. The priinciple is to produce in the field, besicles the images of the eyepiece and objective (whose position may vary), a third image emanating from the axis of rotation, which, completely independent of the flexion of the tubes, undergoes only a slight displacement due to the auxiliary lens. This image serves as a means of estimating the relative displacement of the two others. (A concavo-convex lens is placed in the axis of the central cube, and on its axis of rotation.) - Examples of calculation of the torsion of prisms with mixtilinear base, by $M$. cle Saint-Venant.-On the binary form of the seventh order, by Prof. Sylvester. - Study on ordinary and compound stearn engines, steam jackets, and superheating, according to experimental thermodynamics, (extract), by M. Ledieu. Some observations are here made on neutral spaces and their influence, the restriction of these having been one clirection of recent improvement.-On the works of the Saint Gothard tumel, by M. Colladon. After recounting obstacles which have retarded the work-among others, greatly increased and violent infiltration, and the swelling of a plastic mass of decomposed felspar and gypsum on contact with moist air, exerting tre mendous pressure on supports-he gives information about the air compressing and ventilating apparatus and the boring machines. It is expected that about eight years will suffice for the completion of the worls. The difference between the first estimated and actual expense will, it is thought, be nearly 100 million francs.-On a series of soundings unclertaken by $M$. Rondaire in view of the formation of the African interior sea, by M. De Lesseps. These soundings will cover about 500 leagues, and will occupy $M$. Roudaire about six months, after which it will be possible to estimate fairly the expense of the project. M. De Lesseps describes what he saw of that region. - Report on a memoir of Prof. Lawrence Smith on the native iron of Greenland and the dolerite it contains. The reporters recommend insertion of this interesting memoir in the Recueit des Savants etrangers.-Diseases of plants caused by Peronospora; attempted treatment; application to the lettucedisease, P. Gangliiformis, Berk. Memoir by M. Cornu.-M. Werdermann replied to $M$. Reynier's reclamation of priority with regard to the electric lamp. He maintains that his (W.'s) lamp depends not on the effect of incandescence of a heated carbon, but on an extremely small voltaic arc; the incandescence of a small part of the electrode is merely an inevitable consequence.-On an anto. matic regulator of currents, by $M$. Hospitalier. This consists of a one-layer resistance bobbin, having a portion of its wire laid bare, and in contact with a slightly convex distributor connected with an armature before an electro-magnet which is affected by the current to be regulated.-On a small telephonic apparatus, ly M. Burdet de Paris (sealed packet opened). This refers to a telephone in the form of a watch, which, with a microphone, gives speech well, M. du Moncel referred to a very advanta. geous arrangement of a speaking microphone (by M. Bondet de Paris), which he would shortly describe.-On the reduction, in continuous fractions, of a pretty extensive class of functions, by $M$. Laguerre.-On a point in the history of mathematics, by $M$. Desbovas. - Theorems on prime numbers, by $M$. Protb.-On a remarkable specimen of siliciuret of iron, by Prof.
Lawrence Smith. This piece is remarkably rich in silicium (about I5 per cent.), and is eviclently the product of a blast furnace. There are no such furnaces where it was found, but there are some a few miles away, and about roo miles from the spot was one which supplied iron having 8 per cent. silicium, and gave up working because of want of demand for such iron. Prof. Smith thinks the piece may have been (exceptionally) produced there. M. Daubrée said industry has never been known to produce an alloy of iron with nearly so much silicium. The highest proportion at the Exhibition was Io per cent,-On a new acid obtained from camphor, by $M$. Haller.-On the formation of hexamethylbenzine by the decom. position of acetone, by Mr. Greene. - On normal ethyloxybutyric acid and its derivatives, by $M$. Duvillier.-On the presence of ytterbine in the sipylite of Amherst, by M. DelafontaineExistence of baryta and strontian in all rocks constituting primordial strata; metalliferons veins with gangue of baryta, by $M$. Dieulafait. He infers from the facts that baryta and strontian have the same origin, viz., the primordial rocks; hence the metalliferous ores (manganese, lead, zinc, \&c.), for which baryta serves as gangue, has also this origin:-On the dangers in use of borax for preservation of meat and the reasons why some substances cause meat to lose its nutritive properties, by $M$. Le Bon. He prescribes, in principle, the use of chemical substances, even the apparently inoffensive salt, for preservation of meat. The most nutritive part of meat is the juice, and this, when the meat is put in saline solution or covered with a salt in powder, malies rapid exchange of its nutritive principles throutgh enclosmose. Ife hints at a new mode of preservation, however, other than cold.-On an artificial pyroxene (diopside), by $M$. Gruner,-Influence of atmospheric electricity on fructificatien of plants, by M. Grandeat. It'greatly stimulates the phenomenon. -On a disease of the coffee-tree observed in Brazil, by $M$. Jobert,-On the diffusion of heat by leaves, by M. Masuenne.On the power of absorption of water by wood, by M. Maumené. The property varies (for different woods) between 9.37 and I74.88 per cent. of the absolutely diry wood; the latter figure was obtained with chestnut. On a scientific balloon accent of October $3 \mathrm{I}$, by M. Tridon.

\section{CONTENTS}

Paradoxical Puilosophy. By Prof, J. Ccerk Maxtyell, F.R.S. I I4 Scirnce Class-Books. . . . . . . . . . . . . . . $x_{4}$ OUR BOOK SHElr: :"Studies from the Plyysiological Laboratory in the University of

"The American Quarterly Microscopical Journal, containing the

Transactions of the New York Micruscopical Society" ". . It5

LETTERS TO THE EDTTOR:-

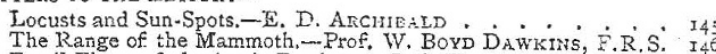

Fossil Floras of the Arctic Regions, - J. J. WILD

The Microphone.-THOS, S. TAIT

Horne Growth of Plants, - Join MuNRo.

Hornets.-WM. WILSON SAUNDERS

Colour-Blindness.-Dr. W. POLE, FR

Magnetic Storm, May ri 882 ,

"Measuring the Height of Clouds." -J. T. WILKE : : * . I4S

The Weather.-G.S. THomson . . . . . . . $r_{4}$

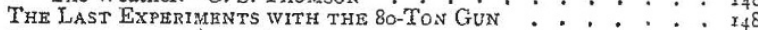

The Registrarship of London Universtty . . . . . . . .

About Fishes' Heads. By Prof. E. Perceval Wright . . , , I49

The Brown Institution . . . . . . . . . . . . . . . . ${ }^{157}$

ON SOME Improved METhODS OF Producing and REgulatinc;

Elietric Light. By H. Wilde (With Illustration) . . . . . I5

INFLUENCr of the Straits of Dover on THE TIDEs of THE

BRITISH ChanNel AND THE North SEA, By Sir William Thon-

SON, F.R.S. (With Illustration). . . . . . . . . . . . . ${ }_{153}$

Our Astronomical Column :-

Occultations of Stars by Jupiter's Satellites . . . . . . . 154

The Conjunction of Mars and Saturn, June 30 , $18799^{\circ}: \dot{*}^{*}: \dot{ }^{*} \mathrm{IS}_{4}$

BIOLOGICAL NOTES:-

Natural Selection among Salamanders . . . . . . . . ${ }^{55}$

The Muscles of the Mammalian Foot . . . . . . . . . I55

Sensitive Organs in Asclepiadacere . . . . . . . . . . . I55

The Inhalation of Phosphuretted Hydrogen . . . . . . . 155

Structure and Affinities of Characea . . . . . . . . . $i 56$

Geographical Notes . . . . . . . . . . . . . 156

The Compound Nature of the Elements . . . . . . . . 157

Notes . . . . . . . . . . . . . . . . . ${ }_{15}$

On Haliotropism in Plants . . . . . . . . . . . . $16 x$

Societies and ACAdemies . . . . . . . . . . . . r6r 